\section{Algebraic Curves}

By Prof. J. G. Semple and G. T. Kneebone. Pp. xiii + 361. (Oxford: Clarendon Press; London: Oxford University Press, 1959.) 45s. net.

$\mathrm{R}^{\mathrm{B}}$ ECENT work on algebraic geometry has been much concerned with placing the subject on foundations which should be genuinely algebraic; a programme set on foot by van der Waerden some twenty-five years ago. The theory of algebraic curves is a very important section of algebraic geometry, and while R. J. Walker's excellent treatise, based on methods of modern algebra, has been available for ten years, an account on similar lines, but tailored to suit the student in his final undergraduate or first postgraduate year, has been needed. This need has now been fully met. Semple and Kneebone start from the beginnings, and take the general theory as far as the Riemann-Poch theorem; the exposition is always clear and precise, and each chapter begins with a survey of what is to be found therein and concludes with valuable exercises and notes. No very extensive algebraic equipment is required in the early stages, and to make the work self-contained an appendix summarizes practically all the needed work on rings, fields, polynomials and elimination theory. Two chapters initiate special studies : that on "Coordinates of a Curve" is a most helpful introduction to the Cayley form for algebraic varieties, while that on "Local Geometry in $\mathrm{S}_{2}$ " deals with a logical algebraic basis for what used to be called 'indefinitely near points'. It should be added that references to the older methods involving algebraic functions and Riemann surfaces are not absolutely excluded. An older generation might ask what Salmon would have made of all this, but, remombering that according to his contemporaries Salmon was "never a calculus man", perhaps he would have come to appreciate this new close convolution of geometry with algebra.

\section{T. A. A. Broadbent}

Chemical Analysis of Resin-based Coating Materials Edited by C. P. A. Kappelmeier. Pp. xxvii +630 . (New York : Interscience Publishers Inc.; London : Interscience Publishers, Ltd., 1959.) 147s.

7 HIS collection of papers on the analysis of coating compositions was edited by an expert in this particular field, the late Dr. C. P. A. Kappelmeier, who studied under Baeyer and Wieland.

The book contains practical contributions from twenty-six senior cnemists of many leading chemical firms situated in all parts of the world. It constitutes a unique and welcome compilation of tested classical and modern methods for the analysis of resins, plastics, paints, solvents, etc.

C. Schwarzenback and W. Schneider present an excellent chapter on the complexometric analyses of metallic additives: A. Z. Conner describes the techniques of paper and columnar chromatography, but gas-liquid chromatography receives only brief mention. Infra-red and ultra-violet absorption methods receive detailed treatment, and even the applications of mass spectrometry are succinctly discussed in the 'rosin' section.

Specialized chapters are devoted to alkyd and synthetic thermoplastic resins, latex paints, cellulose lacquers, drying oils, etc., and much helpful laboratory detail is provided. This volume will undoubtedly prove a most valuable reference work for industrial analysts who are concerned with the quantitative and qualitative examination of the wide range of coating compositions now being manufactured by the chemical industries. It is, unfortunately, rather highly priced for a book of 630 pages, but it is most legible and printed on excellent paper.

D. T. LEwiS

\section{Microbiology}

Historical Contributions from 1776 to 1908 by Spallanzani, Schwann, Pasteur, Cohn, Tyndall, Koch, Lister, Schloesing, Burrill, Ehrlich, Winogradsky, Warington, Beijerinck, Smith, Orla-Jensen. Edited by Raymond N. Doetsch. Pp. xii +233 . (New Brunswick, N.J.: Rutgers University Press, 1960.) 5 dollars.

7 HIS book follows a commendable trend in

American scientific publishing during recent years of presenting, in abridged form, excerpts from the works of the great scientists of the past. For those of us the majority-who will never have an opportunity of reading many of the original papers, such syntheses provide an admirable substitute. As the editor wisely points out, the selection of papers is necessarily arbitrary, and there is bound to be difference of opinion regarding inclusions and omissions. Nevertheless, few will quarrel with the majority of the works included here, each of which is prefaced with a brief biographical introduction and a picture of the author.

The collection will be of value to anyone interested in the history of science, and would be a useful adjunct to any course covering this period of scientific history. It should prove particularly valuable in schools where the historical aspects of scientific discovery tend to be overlooked. The diversity of subjects covered provides a fascinating insight into the manifold applications of the so-called scientific method.

W. H. Dowdeswell

\section{Transactions of the International Astronomical Union}

Vol. 10: Tenth General Assembly held at Moscow, 12-20 August, 1958. Edited by D. H. Sadler. (International Council of Scientific Unions : International Astronomical Union.) Pp. ix +774. (Cambridge : At the University Press, 1960.) 90s. net.

THIS volume contains the Proceedings of the meeting of the International Astronomical Union held in Moscow (1958). It contains the resolutions adopted at that meeting and the reports and proceedings of the various Commissions within the Union. The reports of the Commissions provide valuable summaries of the state of the subject and provide extensive bibliographies of original research done, in the preceding three years, in those fields which come within the scope of the Commissions. Four joint discussions (solar flares and corpuscular streams, nucleogenesis in stars, the luminosity of cepheids and astronomical observations with artificial satellites, rockets and balloons) which took place during the meeting are reported. A list of members of the Union and their addresses, correct to October 1959, together with the membership of the Commissions, is also appended.

It is noted that the General Secretary is contem. plating action to expedite the publication of the Transactions. The rapid publication of the Trans. actions in smaller volumes would certainly enhance their usefulness as a reference work. D. MCNaLLY 